\title{
Second Opinion Reviews for Cancer Diagnoses in Anatomic Pathology: A Comprehensive Cancer Center's Experience
}

\author{
CAROLINA STROSBERG ${ }^{1,2}$, JULIE GIBBS $^{1,2}$, DIANA BRASWELL ${ }^{1,2}$, RONNI R. LESLIE $^{3}$, \\ JANE MESSINA $^{3,4}$, BARBARA A. CENTENO ${ }^{3,4}$ and DOMENICO COPPOLA ${ }^{1,3,4,5}$ \\ Departments of ${ }^{1}$ Chemical Biology Molecular Medicine, ${ }^{3}$ Anatomic Pathology, and \\ ${ }^{5}$ Tumor Biology, H. Lee Moffitt Cancer Center \& Research Institute, Tampa, FL, U.S.A.; \\ Departments of ${ }^{2}$ Pathology and Cell Biology, and ${ }^{4}$ Oncological Sciences, \\ University of South Florida, Tampa, FL, U.S.A.
}

\begin{abstract}
Aim: The objective of this study was to define the rates of discrepancy between outside pathological diagnoses and secondary reviews. Materials and Methods: We assessed the rates of discordance between outside diagnoses and secondary reviews, categorizing by organ site and minor or major (affecting patient care) discordances. Results: A total of 9,289 consecutive surgical pathology (SP) and cytopathology $(C P)$ cases reviewed in 2015 were identified. For 8,191 outside SP cases reviewed, the overall discordance rate (DR) was $14.2 \%$ (2.2\% major, $12.0 \%$ minor). Specifically, neuropathology had the highest DR (10.9\%), cutaneous and breast the lowest $(1.1 \%$ each). Among 1,098 CP cases, the total DR was $13.7 \%$ (3.0\% major, $10.7 \%$ minor $)$. The majority of $C P$ cases $(1,066)$ were non-gynecological and had a total DR of $13.4 \%(2.7 \%$ major, $10.7 \%$ minor). Conclusion: While major DR was low, certain subspecialties had high DRs. This project can help identify areas where focused education could help improve pathological diagnostic accuracy for cancer.
\end{abstract}

Academic cancer centers commonly perform reviews of outside pathological material at the time of initial referral for consultation. Previously reported diagnostic discrepancy rates in pathology have been shown to vary by institution, by organ system, and type of review, ranging from less than $2 \%$ to over 40 (1-49). The Moffitt Cancer Center (MCC) is the only National Cancer Institute-designated Comprehensive Cancer Center based in Florida and is the third largest cancer center in the United States based on patient volume. As such, our

Correspondence to: Domenico Coppola, MD, Department of Anatomic Pathology, H. Lee Moffitt Cancer Center and Research Institute, 12902 Magnolia Dr., Tampa, FL 33612, U.S.A. E-mail: domenico.coppola@moffitt.org

Key Words: Pathology, second opinion, discrepancies, cancer center. anatomic Pathology Department performs large numbers of secondary reviews of pathological material from patients initially seen in community hospitals and clinics, mostly throughout Florida and the southeastern United States, who are referred to our Institution for definitive management of their disease.

The Anatomic Surgical Pathology Services at MCC are an integral part of the multidisciplinary clinical programs, including Breast, Cutaneous, Gastrointestinal, Genitourinary, Gynecological, Head and Neck, Sarcoma, Thoracic and Neuro-Oncology programs. Our pathologists have expertise, and subspecialty training where applicable, in one or more of these programs and participate in their respective multidisciplinary Tumor Board discussions on a weekly basis. These Tumor Boards are held to present challenging cases, including ones with major discordant pathological diagnoses, for discussion and therapeutic recommendations. An example of such a case seen at our Institution was that of a patient who presented with an outside diagnosis of tumoral melanosis. Upon in-house review, a diagnostic discrepancy was found changing the diagnosis to traumatic tattoo. Such a dramatic change in diagnosis from malignant to benign prevented this patient from having to undergo further therapy.

The overall rates of diagnostic discrepancies encountered during review of outside anatomical pathological material in Florida have not been well documented. A thorough evaluation, with special attention to Florida cases, is essential for continued quality improvement of cancer care in this region. We assessed the rates of discordance between outside pathological diagnoses and secondary reviews at MCC, stratifying the results by organ system and by type of specimen from cases received during a 1-year period. We focused on the major diagnostic changes that were expected to result in patient treatment modifications. Nevertheless, we also used this opportunity to evaluate our own guidelines on reporting, documenting and tracking second-opinion review discrepancies as a quality of practice improvement tool. 


\section{Materials and Methods}

A total of 9,289 consecutive surgical and cytological cases sent for second opinion to the MCC in 2015 were retrospectively reviewed. This was a retrospective data review approved by the Institution Review Board (protocol MCC\#19113). The total number of surgical cases received by each program were as follows: breast: 1,445, cutaneous: 810 , gastrointestinal: 2,084, genitourinary: 1,198, gynecological: 606 , head and neck: 621 , neuro: 184 , sarcoma: 306 , and thoracic: 936. The cytopathology cases included 1,066 nongynecological and 32 gynecological cases. The final reports issued by the contributor and by our Pathology Department were compared. Discrepancies were assessed and classified as minor (no expected impact on patient care) and major (potential impact on patient care). For surgical pathology cases, discrepancies encompassed any discordance in the diagnosis including change in tumor grading, tumor staging [tumor size (pT status) or lymph node involvement ( $\mathrm{pN}$ status)], margin status, lymphovascular invasion or perineural invasion status, or other reasons for disagreement between the contributor's and MCC diagnoses. Screening errors were also considered as potential reasons for discrepancy in cytology cases. Our institution uses PathNet and Cerner Millennium (Cerner Corporation, North Kansas City, M, USAO) systems for capturing, tracking and managing the data and Microsoft Excel software was used for the statistical analysis.

Anatomic pathology cases were received from 171 contributing institutions in 2015. The contributors and the type of discrepancies were tabulated and compared. We also further analyzed the major discordance rates of the Florida contributors with the intent to provide feedback to contributors.

\section{Results}

Surgical pathology review cases. Information regarding the discordance between the outside institution (OI) and the MCC diagnoses was available for 8,191 outside surgical pathology review cases in 2015 (Table I, Figure 1). The overall percentage of discordance between the OI and the MCC diagnoses was $14.2 \%$ ( $2.2 \%$ major, $12.0 \%$ minor). The highest percentage of overall discordance was observed in the neuro-oncology program $(52.2 \%$ total discordance, $10.9 \%$ major, $41.3 \%$ minor) and the lowest percentage of overall discordance was observed in the thoracic program (4.3\% total discordance, $2.0 \%$ major, $2.2 \%$ minor). The cutaneous and breast programs had the lowest major discordance rates out of all the programs (1.1\% each).

Among the reviewed surgical cases classified as "major diagnostic discrepancies", change in diagnosis represented the majority of the cases $(75.3 \%)$, followed by change in tumor grade $(10.4 \%)$, and disagreement on pT status $(7.7 \%)$ (Table II). The remaining reasons for disagreement accounted for fewer than $3 \%$ of the total documented reasons.

Cytopathology review cases. Information regarding the discordance of between the OI and the MCC diagnoses was available for 1,066 non-gynecologic cytology and 32 gynecological cytology review cases for 2015 (Table III,
Table I. Discrepancy rates of diagnoses for all outside surgical pathology cases reviewed in 2015 by program.

\begin{tabular}{lccr}
\hline \multirow{2}{*}{ Program } & \multicolumn{3}{c}{ Discrepancy rate } \\
\cline { 2 - 4 } & Major & Minor & Total \\
\hline Breast $(\mathrm{N}=1145)$ & $1.1 \%(\mathrm{~N}=16)$ & $8.0 \%(\mathrm{~N}=116)$ & $9.1 \%$ \\
Cutaneous $(\mathrm{N}=810)$ & $1.1 \%(\mathrm{~N}=9)$ & $6.7 \%(\mathrm{~N}=54)$ & $7.8 \%$ \\
GI $(\mathrm{N}=2084)$ & $2.7 \%(\mathrm{~N}=57)$ & $9.5 \%(\mathrm{~N}=197)$ & $12.2 \%$ \\
GU $(\mathrm{N}=1198)$ & $2.0 \%(\mathrm{~N}=24)$ & $30.7 \%(\mathrm{~N}=368)$ & $32.7 \%$ \\
GYN $(\mathrm{N}=606)$ & $3.3 \%(\mathrm{~N}=20)$ & $6.1 \%(\mathrm{~N}=37)$ & $9.4 \%$ \\
Head \& Neck $(\mathrm{N}=621)$ & $1.4 \%(\mathrm{~N}=9)$ & $13.0 \%(\mathrm{~N}=81)$ & $14.5 \%$ \\
Neuro $(\mathrm{N}=184)$ & $10.9 \%(\mathrm{~N}=20)$ & $41.3 \%(\mathrm{~N}=76)$ & $52.2 \%$ \\
Sarcoma $(\mathrm{N}=306)$ & $2.6 \%(\mathrm{~N}=8)$ & $9.8 \%(\mathrm{~N}=30)$ & $12.4 \%$ \\
Thoracic $(\mathrm{N}=937)$ & $2.0 \%(\mathrm{~N}=19)$ & $2.2 \%(\mathrm{~N}=21)$ & $4.3 \%$ \\
Total $(\mathrm{N}=8191)$ & $2.2 \%(\mathrm{~N}=182)$ & $12.0 \%(\mathrm{~N}=980)$ & $14.2 \%$ \\
\hline
\end{tabular}

GI, Gastrointestinal; GU, genitourinary; GYN, gynecological.

Figure 1). The overall percentage of discordance between the $\mathrm{OI}$ and the MCC diagnoses for non-gynecological cases was $13.4 \%$ (2.7\% major, $10.7 \%$ minor). The overall percentage of discordance for gynecological cytology cases was $21.9 \%$ (12.5\% major, $9.4 \%$ minor). The combined total rate of overall discordance for all cytology cases was $13.7 \%$. (3.0\% major, $10.7 \%$ minor).

Among the reviewed cytopathology cases classified as "major diagnostic discrepancies", $90.9 \%$ of were documented as being due to a change in the diagnosis (Table IV). The remaining documented reasons were related to screening error $(9.1 \%)$. Other reasons for disagreement were classified as either "not applicable" or not selected by the reviewers.

Major discrepancy rates of local contributors. Outside pathological material may be received for review for second opinion by MCC from any national or even international institution. In $2015,139(81 \%)$ of the 171 institutions that contributed material to MCC were from the state of Florida. Since the majority of second opinion review cases seen at our Institution are from Florida contributors, we looked for possible differences in the rates of major diagnostic discrepancies from within the state. Contributors with at least four major diagnostic discrepancies were identified. A total of eight contributors were found to have at least four cases with major anatomical pathological errors. The total number of anatomical pathology cases contributed from each of these institutions to MCC and their rates of major discrepancy for the year 2015 were compared. In Table V, these institutions were listed in order from highest to lowest rate of major discrepancy. For the listed institutions, the major discrepancy rate ranged from $2.7 \%$ to $10 \%$. Contributing institutions $1,3,4,6,7$ and 8 are hospitals, whereas contributing institutions 2 and 5 are medical groups that provide pathology services to the community. 


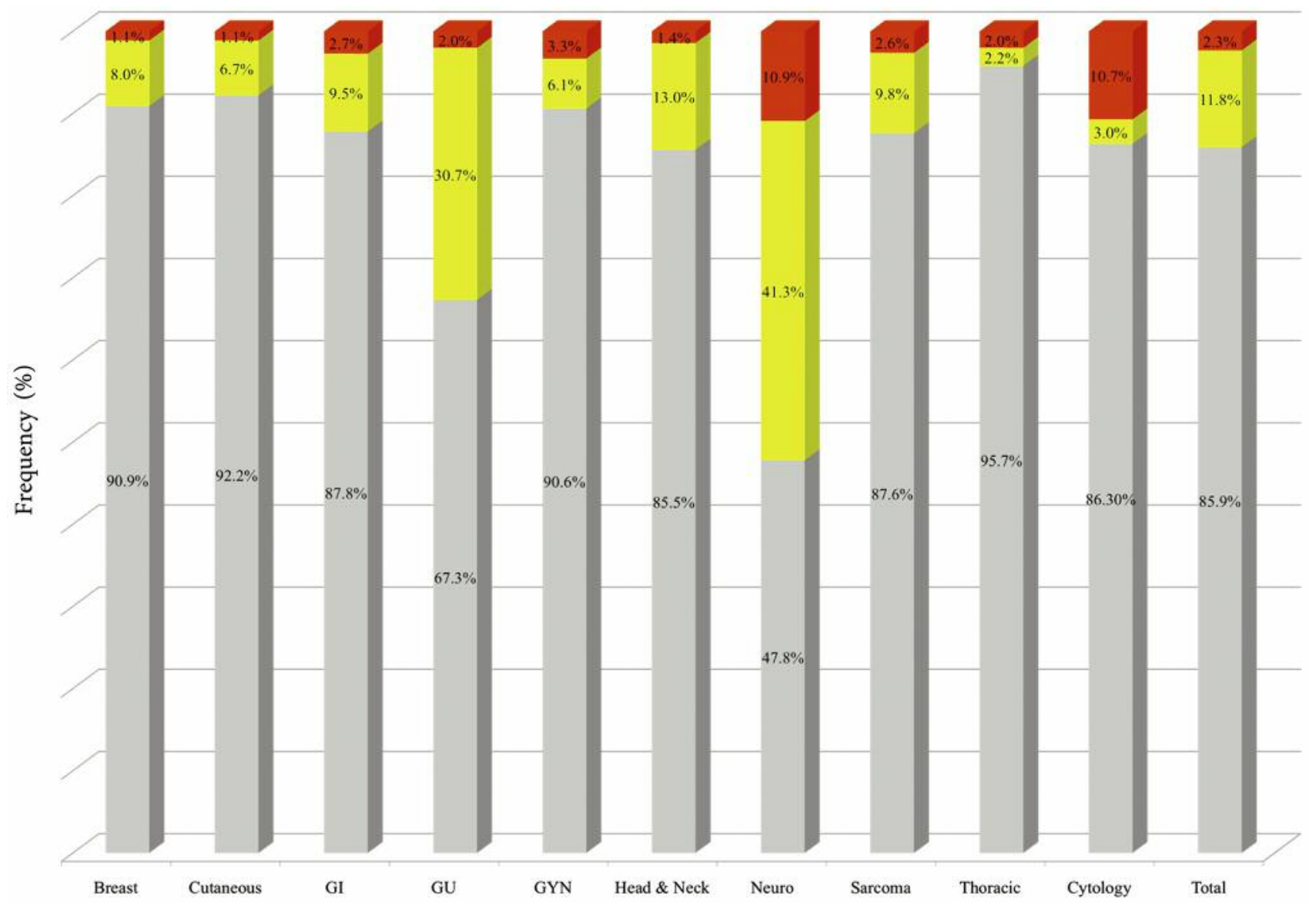

Figure 1. Major and minor discrepancy rates for all outside pathology cases reviewed by program in 2015. Major discrepancies are shown in red, minor discrepancies in yellow, and concordant diagnoses shown in gray. GU, Genitourinary; GI, gastrointestinal; GYN, gynecological.

\section{Discussion}

Reports of the current overall rates of diagnostic discrepancies encountered during review of outside surgical pathology and cytopathology cancer cases are limited. Among the reports available, a recent publication by Middleton et al. from University of Texas MD Anderson Cancer Center reported an overall discrepancy rate of $25 \%$ ( $18.7 \%$ minor, $6.2 \%$ major) on review of 2,718 outside cases contributed to their institution over a 1-month period, with major discrepancies defined as those that potentially affected patient care (6). In 1999, Kronz et al. from Johns Hopkins Medical Institutions showed that $1.4 \%$ of 6,171 cases contributed over a 21-month period for second opinion in surgical pathology had changes in diagnosis, which could potentially result in major therapeutic and prognostic modifications (49). Manion et al., from the University of Iowa, reported $2.3 \%$ major and $9.0 \%$ minor diagnostic discrepancies in 5,629 cases on mandatory review of surgical pathology referral material (16). A report by Raab et al. focused on correlation of cytological and histological diagnoses and detected a frequency of error in cancer diagnosis ranging from $1.79 \%$ to $9.42 \%$ and from $4.87 \%$ to $11.8 \%$ for gynecological and non-gynecological cytology cases, respectively (30).

Some reports reviewed second opinion pathological review for specific organ systems. One report from the United Kingdom found major discrepancies in diagnoses in $16.4 \%$ of 950 cases of soft-tissue sarcomas when referred from the community to a tertiary cancer center (5). Arbiser et al. reviewed 266 soft-tissue pathology consultative second opinion case requests to their Georgia institution that were accompanied by an outside diagnosis and found $25 \%$ major and $7 \%$ minor discrepancies (38). Hahm et al. from Ohio State University reported $31(35.2 \%)$ cases with discrepant diagnoses discovered on review of 194 hepatobiliary and gastrointestinal outside pathology cases, six of which were of major significance (39). Reports of second opinion 
Table II. Reasons for major diagnostic discrepancy for surgical pathology cases reviewed in 2015.

\begin{tabular}{|c|c|c|c|c|c|c|c|c|c|c|}
\hline \multirow{2}{*}{$\begin{array}{l}\text { Reason for major } \\
\text { discrepancy }\end{array}$} & \multicolumn{9}{|c|}{ Program specialty, $n$} & \multirow[t]{2}{*}{ Percentage of total case } \\
\hline & Breast & Derm & GI & GU & GYN & $\mathrm{H} \& \mathrm{~N}$ & Neuro & Sarcoma & Thoracic & \\
\hline Change in diagnosis & 11 & 9 & 36 & 17 & 18 & 6 & 14 & 8 & 18 & $75.3 \%(\mathrm{~N}=137)$ \\
\hline Change in grade & 0 & 0 & 9 & 3 & 1 & 0 & 6 & 0 & 0 & $10.4 \%(\mathrm{~N}=19)$ \\
\hline Change in $\mathrm{pT}$ & 1 & 0 & 7 & 4 & 0 & 2 & 0 & 0 & 0 & $7.7 \%(\mathrm{~N}=14)$ \\
\hline Change in margin & 3 & 0 & 2 & 0 & 0 & 0 & 0 & 0 & 0 & $2.7 \%(\mathrm{~N}=5)$ \\
\hline Change in LVI/PNI & 0 & 0 & 2 & 0 & 0 & 1 & 0 & 0 & 0 & $1.6 \%(\mathrm{~N}=3)$ \\
\hline Change in $\mathrm{pN}$ & 0 & 0 & 0 & 0 & 1 & 0 & 0 & 0 & 0 & $0.5 \%(\mathrm{~N}=1)$ \\
\hline Other & 1 & 0 & 2 & 0 & 0 & 0 & 0 & 0 & 0 & $1.6 \%(\mathrm{~N}=3)$ \\
\hline Total & 16 & 9 & 58 & 24 & 20 & 9 & 20 & 8 & 18 & $100 \%(\mathrm{~N}=182)$ \\
\hline
\end{tabular}

Derm, Dermatopathology; GU, genitourinary; H\&N, head and neck, GI, gastrointestinal; GYN, gynecological; LVI, lymphovascular invasion; PNI, perineural invasion; $\mathrm{pT}$, tumor stage; $\mathrm{pN}$, regional lymph node stage.

Table III. Discrepancy rates of diagnoses for all outside cytopathology cases reviewed in 2015.

\begin{tabular}{lccc}
\hline Cytopathology case type & \multicolumn{3}{c}{ Discrepancy rate } \\
\cline { 2 - 4 } & Major & Minor & Total \\
\hline Non-gynecological $(\mathrm{N}=1,066)$ & $2.7 \%(\mathrm{~N}=29)$ & $10.7 \%(\mathrm{~N}=114)$ & $13.4 \%$ \\
Gynecological $(\mathrm{N}=32)$ & $12.5 \%(\mathrm{~N}=4)$ & $9.4 \%(\mathrm{~N}=3)$ & $21.9 \%$ \\
Total $(\mathrm{N}=1,098)$ & $3.0 \%(\mathrm{~N}=33)$ & $10.7 \%(\mathrm{~N}=117)$ & $13.7 \%$ \\
\hline
\end{tabular}

pathology diagnoses from genitourinary specimens have shown significant discrepancies ranging from $1.2 \%$ to over $40 \%(6,10,11,13,19,49)$. Major changes in second opinion breast pathology diagnoses have been reported in up to $10 \%$ of cases $(4,6,16,49-52)$. A few reports focusing on the impact of second opinion reviews for head and neck pathology cases have shown significant discrepancy rates in up to $17 \%$ of cases $(6,49,53)$.

Quality measures pertinent to this geographical area are represented by limited reports, including one from the Baptist Hospital of Miami (Miami, FL, USA). A total of 8,363 cases underwent blinded review by one or by more pathologists showing that the disagreement rate for cases reviewed only by one pathologist was higher $(6.9 \%)$ compared to cases reviewed by more than one pathologist (4.8\%) (23). A prior report from our Institution, focusing on cases of thin melanoma and melanoma in situ, found a pathological discordance rate of $4 \%$ when reviewing 420 cases (15).

To our knowledge, this study is the first comprehensive analysis of diagnostic discrepancies for cancer diagnoses by organ system in the state of Florida. We focused on 12 months of data available at our Institution from January 1, 2015 to December 31, 2015. We assessed the rates of discordance
Table IV. Reasons for major diagnostic discrepancy for anatomical cytopathology cases reviewed in 2015.

\begin{tabular}{lcc}
\hline $\begin{array}{l}\text { Reason for major } \\
\text { discrepancy }\end{array}$ & $\begin{array}{c}\text { Number of } \\
\text { cases }\end{array}$ & $\begin{array}{c}\text { Percentage of } \\
\text { total cases }\end{array}$ \\
\hline Change in diagnosis & 30 & $90.9 \%$ \\
Screening error & 3 & $9.1 \%$ \\
Other & 0 & $0.0 \%$ \\
Total cases & 33 & \\
\hline
\end{tabular}

Table V. Summary of Florida contributors with at least four major discrepancies in 2015.

\begin{tabular}{lcc}
\hline $\begin{array}{l}\text { Contributing } \\
\text { institution }\end{array}$ & $\begin{array}{c}\text { Number of } \\
\text { cases } \\
\text { reviewed }\end{array}$ & $\begin{array}{c}\text { Percentage of cases } \\
\text { with major } \\
\text { discrepancies }\end{array}$ \\
\hline 1 & 70 & $10 \%(\mathrm{~N}=7)$ \\
2 & 50 & $10 \%(\mathrm{~N}=5)$ \\
3 & 95 & $5.3 \%(\mathrm{~N}=5)$ \\
4 & 212 & $5.2 \%(\mathrm{~N}=11)$ \\
5 & 139 & $4.3 \%(\mathrm{~N}=6)$ \\
6 & 183 & $3.3 \%(\mathrm{~N}=6)$ \\
7 & 162 & $3.1 \%(\mathrm{~N}=5)$ \\
8 & 182 & $2.7 \%(\mathrm{~N}=5)$ \\
\hline
\end{tabular}

between outside pathological diagnoses and secondary opinion reviews at MCC, stratifying the results by program, type of specimen (surgical versus cytology), and reasons for discrepancy (major and minor) based on patient impact.

Analysis of likely causes for the results at our Institution leads to several possibilities. It is likely that some discrepancies are subspecialty-specific. For example, neuropathology is a 
subspecialty with a low number of specialty-trained practitioners nationally. As a result, the cases are often signed out by general pathologists and when reviewed by a neuropathology specialist in a major cancer center such as ours, discrepancies in the diagnostic criteria could be expected. In contrast, most dermatopathology cases are signed out by a Board-certified dermatopathologist, especially in cases of melanocytic lesions. In breast pathology, the low number of discrepancies observed could be related to the reporting guidelines, which are explicitly widely disseminated and tend to be followed by both academic and community practices.

We also analyzed possible differences in the rates of major diagnostic discrepancies by contributing institution and focused on the local institutions within the state of Florida with the highest number of major diagnostic discrepancies. A total of eight contributors were found to have at least four cases with major anatomical pathology discrepancies in 2015 (Table V). The major discrepancy rate among the contributing institutions varied from $2.7 \%$ (five cases out of 182 submitted cases) to $10 \%$ (seven out of 70 cases submitted). Based on this study, we found no trend regarding whether a contributor from a hospital or medical group had a higher rate in major discrepancies. In cases of high rates of major discrepancies, we contact the contributor institution to discuss the changes made on the report.

\section{Conclusion}

We found that while the overall rate of discrepancies between outside pathological diagnosis and MCC review was low, there were certain subspecialties with higher rates of discordance. In order to improve the quality of diagnostic pathology in the state of Florida, we plan to focus educational efforts on these subspecialties. We will also continue to update our guidelines on communication of discrepancies to referring institutions and treating clinicians.

\section{Conflicts of Interest}

The Authors declare that there is no conflict of interest in regard to this study.

\section{References}

1 Akyildiz EU: Intraoperative pathology consultation for pulmonary lesions: errors and deferrals. Int J Clin Exp Pathol 8: 7961-7966, 2015.

2 Zabielinski M, Leithauser L, Godsey T and Gloster HM Jr.: Laboratory errors leading to nonmelanoma skin cancer recurrence after mohs micrographic surgery. Dermatol Surg 41 : 913-916, 2015.

3 Nakhleh RE, Nose V, Colasacco C, Fatheree LA, Lillemoe TJ, McCrory DC, Meier FA, Otis CN, Owens SR, Raab SS, Turner RR, Ventura CB and Renshaw AA: Interpretive diagnostic error reduction in surgical pathology and cytology: Guideline from the
College of American Pathologists Pathology and Laboratory Quality Center and the Association of Directors of Anatomic and Surgical Pathology. Arch Pathol Lab Med 140(1): 29-40, 2016.

4 Marco V, Muntal T, Garcia-Hernandez F, Cortes J, Gonzalez B and Rubio IT: Changes in breast cancer reports after pathology second opinion. Breast J 20: 295-301, 2014.

5 Thway K, Wang J, Mubako T and Fisher C: Histopathological diagnostic discrepancies in soft tissue tumours referred to a specialist centre: reassessment in the era of ancillary molecular diagnosis. Sarcoma 2014: 686902, 2014.

6 Middleton LP, Feeley TW, Albright HW, Walters R and Hamilton SH: Second-opinion pathologic review is a patient safety mechanism that helps reduce error and decrease waste. J Oncol Pract 10: 275-280, 2014.

7 Mahe E, Ara S, Bishara M, Kurian A, Tauqir S, Ursani N, Vasudev P, Aziz T, Ross C and Lytwyn A: Intraoperative pathology consultation: error, cause and impact. Can J Surg 56: E13-18, 2013.

8 Matasar MJ, Shi W, Silberstien J, Lin O, Busam KJ, TeruyaFeldstein J, Filippa DA, Zelenetz AD and Noy A: Expert secondopinion pathology review of lymphoma in the era of the World Health Organization classification. Ann Oncol 23: 159-166, 2012.

9 Al-Maghrabi JA and Sayadi HH: The importance of second opinion in surgical pathology referral material of lymphoma. Saudi Med J 33: 399-405, 2012.

10 Barqawi AB, Turcanu R, Gamito EJ, Lucia SM, O'Donnell CI, Crawford ED, La Rosa DD and La Rosa FG: The value of second-opinion pathology diagnoses on prostate biopsies from patients referred for management of prostate cancer. Int J Clin Exp Pathol 4: 468-475, 2011.

11 Wayment RO, Bourne A, Kay P and Tarter TH: Second opinion pathology in tertiary care of patients with urologic malignancies. Urol Oncol 29: 194-198, 2011.

12 Sharif MA and Hamdani SN: Second opinion and discrepancy in the diagnosis of soft tissue lesions at surgical pathology. Indian J Pathol Microbiol 53: 460-464, 2010.

13 Jara-Lazaro AR, Thike AA and Tan PH: Diagnostic issues in second opinion consultations in prostate pathology. Pathology 42: 6-14, 2010.

14 Roy JE and Hunt JL: Detection and classification of diagnostic discrepancies (errors) in surgical pathology. Adv Anat Pathol 17: 359-365, 2010.

15 Santillan AA, Messina JL, Marzban SS, Crespo G, Sondak VK and Zager JS: Pathology review of thin melanoma and melanoma in situ in a multidisciplinary melanoma clinic: impact on treatment decisions. J Clin Oncol 28: 481-486, 2010.

16 Manion E, Cohen MB and Weydert J: Mandatory second opinion in surgical pathology referral material: clinical consequences of major disagreements. Am J Surg Pathol 32: 732-737, 2008.

17 Nakhleh RE: Patient safety and error reduction in surgical pathology. Arch Pathol Lab Med 132: 181-185, 2008.

18 Raab SS, Grzybicki DM, Mahood LK, Parwani AV, Kuan SF and Rao UN: Effectiveness of random and focused review in detecting surgical pathology error. Am J Clin Pathol 130: 905912, 2008.

19 Thomas CW, Bainbridge TC, Thomson TA, McGahan CE and Morris WJ: Clinical impact of second pathology opinion: a longitudinal study of central genitourinary pathology review before prostate brachytherapy. Brachytherapy 6: 135-141, 2007. 
20 Renshaw AA and Gould EW: Measuring errors in surgical pathology in real-life practice: defining what does and does not matter. Am J Clin Pathol 127: 144-152, 2007.

21 Kornstein MJ and Byrne SP: The medicolegal aspect of error in pathology: a search of jury verdicts and settlements. Arch Pathol Lab Med 131: 615-618, 2007.

22 Frable WJ: Surgical pathology - second reviews, institutional reviews, audits, and correlations: What's out there? Error or diagnostic variation? Arch Pathol Lab Med 130: 620-625, 2006.

23 Renshaw AA and Gould EW: Measuring the value of review of pathology material by a second pathologist. Am J Clin Pathol 125: 737-739, 2006.

24 Leong AS, Braye S and Bhagwandeen B: Diagnostic 'errors' in anatomical pathology: relevance to Australian laboratories. Pathology 38: 490-497, 2006.

25 Coffin CM: Pediatric surgical pathology: pitfalls and strategies for error prevention. Arch Pathol Lab Med 130: 610-612, 2006.

26 Nakhleh RE: Error reduction in surgical pathology. Arch Pathol Lab Med 130: 630-632, 2006.

27 Renshaw AA: Comparing methods to measure error in gynecologic cytology and surgical pathology. Arch Pathol Lab Med 130: 626-629, 2006.

28 Sirota RL: Defining error in anatomic pathology. Arch Pathol Lab Med 130: 604-606, 2006.

29 Federation nationale des centres de lutte contre le c, Standards OeR, Contre le Cancer LL, Societe Francaise de P, Federation francaise de Cancerologie des CHG, Federation Hospitaliere de $\mathrm{F}$ and Federation nationale de Cancerologie des C: [Standards, Options and Recommendations 2004: good practice guidelines for second opinion in anatomic and surgical pathology in oncology (integral report)]. Ann Pathol 25: 149-171, 2005.

30 Raab SS, Grzybicki DM, Janosky JE, Zarbo RJ, Meier FA, Jensen $\mathrm{C}$ and Geyer SJ: Clinical impact and frequency of anatomic pathology errors in cancer diagnoses. Cancer 104: 2205-2213, 2005.

31 Foucar E: Classification of error in anatomic pathology: a proposal for an evidence-based standard. Semin Diagn Pathol 22: 139-146, 2005.

32 Sirota RL: Error and error reduction in pathology. Arch Pathol Lab Med 129: 1228-1233, 2005.

33 Zarbo RJ, Meier FA and Raab SS: Error detection in anatomic pathology. Arch Pathol Lab Med 129: 1237-1245, 2005.

34 Hollensead SC, Lockwood WB and Elin RJ: Errors in pathology and laboratory medicine: consequences and prevention. J Surg Oncol 88: 161-181, 2004.

35 Valenstein PN and Sirota RL: Identification errors in pathology and laboratory medicine. Clin Lab Med 24: 979-996, vii, 2004.

36 Raab SS: Improving patient safety by examining pathology errors. Clin Lab Med 24: 849-863, 2004.

37 Renshaw AA, Cartagena N, Granter SR and Gould EW: Agreement and error rates using blinded review to evaluate surgical pathology of biopsy material. Am J Clin Pathol 119: 797-800, 2003.
38 Arbiser ZK, Folpe AL and Weiss SW: Consultative (expert) second opinions in soft tissue pathology. Analysis of problemprone diagnostic situations. Am J Clin Pathol 116: 473-476, 2001.

39 Hahm GK, Niemann TH, Lucas JG and Frankel WL: The value of second opinion in gastrointestinal and liver pathology. Arch Pathol Lab Med 125: 736-739, 2001.

40 Renshaw AA: Measuring and reporting errors in surgical pathology. Lessons from gynecologic cytology. Am J Clin Pathol 115: 338-341, 2001.

41 Foucar E: Error in anatomic pathology. Am J Clin Pathol 116 Suppl: S34-46, 2001.

42 Sirota RL: The Institute of Medicine's report on medical error. Implications for pathology. Arch Pathol Lab Med 124: 16741678, 2000.

43 Gibbs J, Henderson-Jackson E and Bui MM: Bone and softtissue pathology: diagnostic and prognostic implications. Surg Clin North Am 96: 915-962, 2016.

44 Selman AE, Niemann TH, Fowler JM and Copeland LJ: Quality assurance of second opinion pathology in gynecologic oncology. Obstet Gynecol 94: 302-306, 1999.

45 Goldstein NS: Diagnostic errors in surgical pathology. Clin Lab Med 19: 743-756, v, 1999.

46 Foucar E: Error identification: a surgical pathology dilemma. Am J Surg Pathol 22: 1-5, 1998.

47 Nakhleh RE and Zarbo RJ: Amended reports in surgical pathology and implications for diagnostic error detection and avoidance: a College of American Pathologists Q-probes study of 1,667,547 accessioned cases in 359 laboratories. Arch Pathol Lab Med 122: 303-309, 1998.

48 Leslie KO, Fechner RE and Kempson RL: Second opinions in surgical pathology. Am J Clin Pathol 106: S58-64, 1996.

49 Kronz JD, Westra WH and Epstein JI: Mandatory second opinion surgical pathology at a large referral hospital. Cancer 86: 2426-2435, 1999.

50 Masood S: Minimizing errors in breast pathology: a call for action. Breast J 21: 333-336, 2015.

51 Geller BM, Nelson HD, Carney PA, Weaver DL, Onega T, Allison KH, Frederick PD, Tosteson AN and Elmore JG: Second opinion in breast pathology: policy, practice and perception. J Clin Pathol 67: 955-960, 2014.

52 Bleiweiss IJ and Raptis G: Look again: the importance of second opinions in breast pathology. J Clin Oncol 30: 2175-2176, 2012.

53 Hamady ZZ, Mather N, Lansdown MR, Davidson L and Maclennan KA: Surgical pathological second opinion in thyroid malignancy: impact on patients' management and prognosis. Eur J Surg Oncol 31: 74-77, 2005.

Received January 7, 2018

Revised February 23, 2018 Accepted March 8, 2018 